ISSN: 2162-3104 Print/ ISSN: 2166-3750 Online

Volume 7, Issue 3 (2017), pp. 728-743

(C) Journal of International Students

http://jistudents.org/

doi: 10.5281/zenodo. 570030

\title{
Instructional Insights Gained From Teaching a Research Methods Course to Chinese International Graduate Students Studying in Canada
}

\author{
Jacqueline L. Beres and Vera E. Woloshyn \\ Brock University, Canada
}

\begin{abstract}
Chinese students represent an increasing proportion of the student body in Canadian postsecondary institutions (Citizenship and Immigration Canada, 2015). While studying abroad, many of these students face linguistic and sociocultural challenges (Zhang, 2016), resulting in calls for Western instructors to provide linguistically and culturally sensitive instruction (Lin \& Scherz, 2014). In this qualitative study, we utilized a form of reflexive ethnography (Enfield \& Stasz, 2011) to outline our experiences teaching a required research methodology course to Chinese graduate students. Specifically, we discuss our pedagogical efforts in context of utilizing students' reported research experiences, facilitating their acquisition of subject-specific vocabulary, and fostering a collaborative learning environment. We conclude by offering instructional suggestions to others who teach research methodologies to Chinese students.
\end{abstract}

Keywords: Chinese graduate students; research methods; co-instruction; reflexive ethnography

Internationalization, which is defined as "the process of integrating an international, intercultural, or global dimension into the purpose, functions or delivery of postsecondary education” (Knight, 2003, p. 2), has become an important issue in higher education. Canadian universities have placed increasing emphasis on internationalization, with nearly all institutions including internationalization in their strategic planning (Universities Canada, 2014). As part of this international focus, Canada and other western countries are hosting greater numbers of international students, particularly those from China (Citizenship and Immigration Canada [CIC], 2015). 
International students bring different values, expectations, and behavioral norms into the classroom. Consequently, instructors must be aware of, and respond to, these differences. In an attempt to understand the diverse students present in their classrooms, instructors may seek generalized understandings of their students, especially as it pertains to culture, pluralities, and associated learning styles. At the same time, instructors must take care to acknowledge diversity across and among students (Louie, 2005), responding to increasing calls to be linguistically and culturally sensitive while avoiding overgeneralizations (Lin \& Scherz, 2014; Ryan \& Carroll, 2005).

Cao, Li, Jiang, and Bai (2014) found that faculty commitment was a key factor in the success of internationalization. For faculty who engaged in teaching international students, support for internationalization efforts and sense of readiness to engage in teaching international students were found to be motivational factors in their work with international students. While some instructors embrace teaching international students, many others shy from these experiences, viewing this instruction as adding to an already full workload (Ryan \& Hellmundt, 2005). These sentiments may be exacerbated in part by a sense of isolation that can be associated with teaching at the postsecondary level (Bryant, Niewolny, Clark, \& Watson, 2014), especially with respect to opportunities for sharing instructional experiences and challenges. Our review of the literature suggested a seeming lack of research documenting instructors' course-specific lived experiences teaching international students. In this paper, we share our experiences as coinstructors of a mandatory research methods course to a cohort of predominantly Chinese students enrolled in a Master of Education (MEd) program. In order to make meaning of our instructional experiences, we first review literature related to common linguistic and sociocultural challenges experienced by many Chinese students enrolled in international programs. After contextualizing the program and ourselves, we then describe our reflexive processes (Enfield \& Stasz, 2011) and associated data collection and analysis strategies.

\section{LITERATURE REVIEW}

The number of international students attending Canadian schools has increased significantly over the past 20 years. In 2013, over 300,000 international students held valid international study permits to study in Canada (CIC, 2015). Studying abroad offers students the chance to explore different cultures, learn new ways of thinking and behaving, make new friends, and improve their cross-cultural knowledge and skills (Andrade, 2006; Zhang, 2016). The majority of international students who study in Canada arrive from Asia and represent diverse provinces and regions throughout China (CIC, 2015). Of these students, the majority enroll in 
postsecondary programs, with just under half (42\%) engaged in undergraduate or graduate studies (CIC, 2015; Government of Canada, 2015). Chinese students, in part, are drawn to Canada because of its multicultural society and relative safety. Canadian postsecondary institutions also typically offer quality academic programming with moderate tuition and living costs (CIC, 2015: Li, DiPetta, \& Woloshyn, 2012). While increasing numbers of international students remain in Canada upon graduation, many others return to their home countries, bringing with them critical knowledge, skills, and lived experiences that are vital for continued economic and social advancement (Altbach \& Reisberg, 2013; Government of Canada, 2015).

Despite their increased presence on campus, many international students, including those enrolled in graduate programs, experience considerable challenges and stresses when studying abroad. For the most part, these tensions reflect unfamiliarity and difficulties with the linguistic and sociocultural elements of the postsecondary environment (e.g., Ying, 2012; Zhang, 2016). For instance, Asian graduate students express concerns related to the pacing and comprehension of lecture materials, use of unfamiliar vocabulary and subject-specific jargon, and knowledge presuppositions. Students similarly express concerns about assignment ambiguity, especially when rubrics and grading guides are absent or when exemplars hold meaning only in context of the dominant culture. They describe exerting considerable effort in order to complete required readings and assignments, with these demands exacerbated by additional requirements to engage in English language training or other supplementary courses (Lin \& Scherz, 2014; Zhang, 2016).

Chinese students' language difficulties often are compounded by sociocultural factors, resulting in acculturation stress. For the most part, Chinese embrace collectivist, high-context worldviews where the identity of the self is defined predominantly in context of relationships with others (Kim, Pan, \& Park, 1998; Sue, 2013). Role expectations within Chinese culture are hierarchical and clearly defined, with youth expected to demonstrate deference, obedience, and respect to elders (including teachers) well into adulthood (Cortazzi \& Jin, 1996; Liu \& Jackson, 2011) and where academic success often is equated to social success (Ying, 2012). Chinese culture also holds strong expectations for self-concealment and modesty, with many students describing themselves as introverted and shy. Accordingly, Chinese typically demonstrate heightened self-awareness and sensitivity to their social environments (Sue, 2013).

For many Chinese students, international study is associated with geographic separation from family and friends and with increased demands for independent living in an unfamiliar context (Ying, 2012). In addition, many Chinese students experience hostility, discrimination, racism, and 
negative stereotyping (Tsai \& Wong, 2012), with students often reporting that they experience stress, anxiety, loneliness, and homesickness (Han, Han, Luo, Jacobs, \& Jean-Baptiste, 2013; Li, Liu, Wei, \& Lan, 2013; Sherry, Thomas, \& Chui, 2010).

Many international Chinese students describe tensions related to their relationships with professors and domestic classmates. For instance, many Asian students express discomfort with student-centered learning approaches (e.g., small-group discussions, questioning, critiquing) where the role of the instructor is deemphasized in favour of student-constructed knowledge (Lin \& Scherz, 2014; Zhang, 2016). Instead, many students place value on instructional methods such as vocabulary practice, active reflection, and repeated review associated with rote learning (Li \& Cutting, 2011). Chinese students typically are accustomed to classroom cultures that feature linear knowledge transmission between instructors and students, with additional reliance on textbooks and other authoritative materials. Consequently students may have difficulties navigating classrooms where peer-led discussions or instructor humor feature prominently (Parris-Kidd \& Barnett, 2011).

The fear of losing face as well as reticent personality tendencies towards shyness and modesty also may leave many Chinese students reluctant to participate in group discussions. This is especially true when students are uncertain about expectations or concerned about offending others, or when they feel they have not yet reached a certain level of mastery, thus rendering them virtually silent in classrooms (Durkin, 2011; Liu \& Jackson, 2011; Parris-Kidd \& Barnett, 2011; Zhang, 2016). Similarly, many students demonstrate reluctance approaching instructors for assistance, even when invited to do so (Lin \& Scherz, 2014). From a pedagogical perspective, it is important for instructors to be aware of these linguistic and sociocultural challenges and preferences, as they will likely have an impact on student learning, with the effects being felt inside and outside of the classroom.

While there is increased understanding of the challenges and complexities that many Chinese graduate students experience as part of their international studies, there is seemingly less information about faculty's direct experiences instructing this diverse group of graduate students. The literature seems to be especially lacking when studies exploring the graduate student-faculty advisor research relationship (e.g., Nguyen, 2013; Ku, Lahman, Yeh, \& Cheng, 2008) are excluded. A variety of factors influence faculty members' engagement in teaching international students. In their study of faculty motivations and behaviours, Cao and colleagues (Cao et al., 2014) found that faculty who believed that internationalization is important and felt a sense of responsibility for teaching international students typically were motivated to take up culturally sensitive practices (e.g., speaking 
slowly, non-verbal communications). When teaching international students, it is important that instructors do not make assumptions about how international students learn (Ryan \& Hellmundt, 2005). While often viewed as a one-way relationship, teaching international students offers an excellent opportunity for faculty members to develop dynamic interactions and increase their own understanding of a range of cultures.

Understanding instructors' general teaching experiences is especially important in context of the increasing availability and popularity of course-only graduate programs in Canada and elsewhere (Canadian Association for Graduate Studies, 2006), where instructors have a direct influence on international students' daily experiences. The purpose of this study is to reflect and deconstruct our instructional experiences teaching a required graduate-level course in research methodologies to a cohort of predominantly international Chinese graduate students. We situated our study within the framework of social constructivism, acknowledging the coconstruction of knowledge and the existence of multiple understandings and perspectives (Schwandt, 2000).

\section{RESEARCH METHOD}

Given the critical importance of contextual factors, we first provide an overview of the MEd program, situate ourselves as co-instructors, describe our course context and organization, and then detail our data collection and analysis procedures.

\section{Program Context}

The Master of Education International Student Program (MEd ISP) was initiated over a decade ago and is hosted in a medium sized comprehensive university located in Southern Ontario, Canada. The MEd ISP operates as a self-contained 14-month, course-based cohort program. As part of the program, students are provided with modest language support (typically for formal written assignments) and cultural excursions. They also are provided with opportunities to engage in domestic classes and researchbased exit courses, albeit these options are seldom taken up in practice ( $\mathrm{Li}$, 2016; Li et al., 2012). In the academic year in which this study was completed, there were a total of 48 students divided into three sections of 16 students. The majority of students were female and from mainland China where they completed undergraduate programs in diverse disciplines (e.g., education, English and foreign language instruction, journalism). Prior to beginning the MEd ISP program, some students had completed various types of education in North America, including master's degree preparation courses, while others entered directly after completing their schooling in China. 


\section{Situating Ourselves and Our Pedagogical Framework}

We are two female educators who volunteered to engage in coinstruction within the international student program. Our willingness to engage with the cohort, in part, was driven by our personal beliefs about the importance of internationalization and a desire to work with diverse student populations. At the same time, we possessed relatively few experiences working with Chinese students and were largely naive about Chinese culture and learning expectations. Jacqueline is a doctoral student and a novice instructor. Teaching the research methodology course represented her first official instructional opportunity. During her master's degree, Jacqueline completed an elective class within the MEd ISP. She subsequently served as a language support assistant for the MEd ISP, where she assisted students with their written communication, giving her a cursory introduction to working with Chinese international students. Vera is a long-term faculty member with extensive experience teaching the introductory methodology course to domestic students, but with only cursory experience with the international program.

We framed our instructional practices within pedagogical principles associated with Western notions of psychological constructivism (Yilmaz, 2008), recognizing the importance of social interactions in promoting individuals' abilities to make meaning and form connections between new and existing knowledge (Vygotsky, 1986). Similarly, we recognized the importance of language in learning and drew upon Bruner's theory of instructional scaffolding (Wood, Bruner, \& Ross, 1976), which emphasizes the use of verbal cues and prompts as learning guides.

\section{Course Context and Organization}

Our course was a 36-hour mandatory research methods course consisting of 12, 3-hour classes. Students enrolled in the course in the fall semester, having completed two introductory, 4-week summer courses. We assumed that most students would not be fully acclimatized to the program, but rather in an adaption stage where they derived comfort from being with other international students (Zhou, Topping, \& Jindal-Snape, 2011). We also anticipated that most students would enter the course with some trepidation, similar to the concerns reported by domestic graduate students completing research courses (Early, 2013).

When designing this course, we intentionally adopted an evaluative (consumer) approach to understanding research versus a generation (production) approach, believing that the former would serve students best by facilitating the development of foundational skills that would enable them to be life-long critical consumers of information (Rodriguez \& Toews, 2005). We presented the research process as a series of interconnected researcher-informed decisions. We emphasized the centrality of the research 
question in guiding subsequent decisions related to design and data analysis, as well as in providing the foundation around which results and implications are considered. We presented the process of critique as a balanced exercise that acknowledged methodological strengths and potential areas for improvement.

We began the course by focusing on an overview of the research process in its entirety. We then explored research literature in general, with a specific focus on conducting a literature review. Next we spent a substantial amount of time examining quantitative research designs, developing research questions and hypotheses, deconstructing data collection and data analysis procedures (including strategies for increasing reliability and validity), and forming interpretations and implications. We then examined these same topics from a qualitative perspective, making appropriate substitutions when relevant (i.e., substituting purpose statements for research hypotheses). Throughout the course we revisited discussions regarding ethics in research and philosophical approaches to conducting research. Our co-instructional approach included collaboratively developing our course syllabi, lecture materials, assignments, and classroom activities. While we delivered our lectures independently, we remained in constant communication throughout the term.

Consistent with recommendations related to exploring topics of common interest when working with international students (McLean \& Ransom, 2005), we incorporated a central theme related to promoting wellbeing and stress management while being a graduate student. We believed that this theme would be of interest to our students and one that they might find beneficial in their daily lives. We consciously wove this theme into many of our weekly class activities and assignments. For example, students practiced their literature search skills by finding research relevant to stress management and wellbeing. They also demonstrated their understanding of qualitative and quantitative research methods by analyzing and critiquing articles about stress management and wellbeing.

\section{Data Collection and Analysis}

In this study, we adopted a form of reflexive ethnography similar to the approach used by Enfield and Stasz (2011) in their examination of their co-teaching experiences. Describing their approach as "neither fully rhetorical nor fully empirical" (p. 109), Enfield and Stasz drew from reflexive ethnography, which examines cultural phenomena. The authors incorporated a semi-structured reflective process and emphasized the cyclical nature of their method, where the researcher affects the research context, and the research context in turn affects the researcher. Mirroring Enfield and Stasz (2011), we met at least once per week in order to debrief our classes. Our discussions were audio recorded and subsequently 
transcribed. We focused on our interpretations of what went well, what needed improvement, and specific concerns about students' progress.

Our reflective process also incorporated elements of action research (Given, 2008), as we engaged in a process of inquiry into our teaching processes. Through weekly sharing of our instructional processes, we hoped that we could learn from our students' and each other's lived experiences. In these ways, we were both researchers and participants, following a cyclical process of observation, informal data collection, collective analysis, and collaborative implementation.

Data analysis included reading and re-reading of the transcriptions of our instructional debriefings. We employed an inductive coding method, where we independently completed open coding by hand (Charmaz, 2014). We then met to share our findings and associated interpretations with the intention of identifying critical teaching moments, instructional challenges, cultural elements, and related insights. Overall, we had strong agreement regarding our primary themes and findings. Where we identified different examples of a particular theme, we discussed any minor discrepancies and came to a mutual understanding. These varied interpretations are acceptable (Armstrong, Gosling, Weinman, \& Marteau, 1997) in light of the nuances of our weekly interactions with the specific students in our respective classrooms. We then selected instructional examples from the beginning, middle, and end of the course that illustrated all components of the course and its foci (e.g., classroom instruction, in-class activities, assignments).

As with any qualitative research study, the trustworthiness of our data needed to be considered (Lincoln \& Guba, 1985). To increase the transferability of our findings, we provided detailed descriptions of the context in which this study was conducted so that comparisons to other pedagogical contexts may be made (Shenton, 2004). We offered rich yet concise descriptions of data to enable a robust understanding of our findings. Finally, to assist with replicability, we documented the specific methodological and pedagogical processes undertaken in this study.

\section{INSTRUCTIONAL PRACTICES AND INSIGHTS}

As a result of our ethnographic reflections, we identified three overarching themes from our co-instructional experiences. These themes describe our pedagogical efforts to use students' reported research experiences in meaningful ways, facilitate their acquisition of subject-specific vocabulary, and foster a collaborative learning environment.

\section{Using Students’ Reported Research Experiences}

As constructivists, we were committed to advancing students' knowledge by associating new information with their existing experiences (Yilmaz, 2008). Consistent with Knowles' (1981) principles of andragogy, 
we hoped to build upon students' previous research experiences, situating new material with previous understandings. However, assessing students' knowledge and experience became a somewhat complicated process given what appeared to be linguistic and conceptual discrepancies between our assumptions and students' understandings about the nature of research.

We began our course by asking students to indicate their familiarity with the research process. Many students responded affirmatively, stating that they had completed a research-based thesis during their undergraduate programs (a response that we interpreted as consistent with engagement in knowledge-production research activities). When students were prompted to further explain, students revealed that completing a thesis involved writing a literature review using secondary sources such as books or book chapters. Other students indicated that they had engaged in research because they had completed questionnaires and surveys that they believed were for research purposes. One student noted that she had completed several questionnaires that related to various aspects of daily life, which would contribute to other research studies, but that she had not explicitly conducted research herself. A few students described their experiences in a previous research methods course where they completed a mini-observation of a common area on campus. A smaller group indicated that they had responded to campus advertisements soliciting research participants, with only one or two students describing instances when they engaged in research-related knowledge generation activities consistent with our Western notions of research production. Jacqueline remarked on the disconnect between students' understanding of research engagement and our assumptions of research production, saying "Oh gosh we have a disconnect between the language or the understanding here.”

Recognizing this disconnect early on in the teaching process allowed us to avoid assumptions that could have had negative consequences for students' learning and allowed us to integrate their reported research experiences within our classes. For instance, we used students' lived experiences as research and marketing participants as starting points for considering researchers' underlying methodological frameworks, motivations, data collection tools, and decision-making processes. In one class, Vera asked a student who had recently participated in a video game study to assume the role of the researcher and invite potential participants into the study. The role play then was used to guide a discussion about ethical considerations including participants' rights and privileges.

[I asked the student], 'what did the researcher tell you when you came in the room?...I want you to be a researcher and I want you to invite Josephine into the study and I want you to invite Samantha. What are you going to say?' ... and then I was able to sort of tweak 
it a little bit. 'If you were doing a marketing survey how would you approach someone in a store?' We played out some scenarios and it was helpful. (Vera).

Incorporating students' reported research experiences into classroom discussions and activities (versus dismissing them) also provided benchmarks for students to monitor their learning, with many students commenting about the limitations of their previous experiences. Jacqueline reflected on a conversation with a student who discussed how completing the course provided additional insights into his professional experiences, and allowed him to recognize that his previous research conducting surveys "wasn't as professional and scientific as the research we are talking about [in class]."

While students' initial responses suggested they were experienced in knowledge production and understood methodological frameworks, in reality students' experiences did not align with our notions of research engagement (i.e., research generation). Accepting students' responses at face value without exploration could have provided an inflated estimate of their knowledge and understandings, and may have led us to advance the curriculum inappropriately. Furthermore, we suspect that our students would have done little to correct these misconceptions or articulate gaps in their knowledge due to cultural practices related to self-containment (Zhang, 2016). Like McLean and Ransom (2005), we caution instructors against making assumptions about students' reported experiences or understandings. Instead we encourage instructors to deconstruct students' stated knowledge and experiences carefully and completely, incorporating students' lived experiences into course material in meaningful ways.

\section{Facilitating Acquisition of Subject-Specific Vocabulary}

Many of our students seemingly struggled with language expression and reception, both in terms of English and the nuances specific to research terminology, with this challenge likely affecting all aspects of their course engagement. Consequently, and consistent with Li and Cutting (2011), we intentionally focused on direct teaching of research-related vocabulary and minimized written language requirements typically associated with knowledge demonstration.

Research-related vocabulary instruction became an important element in our classes. Specifically, we provided direct vocabulary instruction at the start of each instructional unit. This instruction included reviewing lists of predetermined terminology (e.g., qualitative research, case study, phenomenology, quantitative research, independent variable, dependent variable, quasi-experiment) and studying related terms in context of their meaning and morphology. Instruction often included the use of 
mnemonics and other learning aids intended to assist students in recognizing terms quickly and accessing their meanings accurately. Vocabulary instruction was extended to include having students identify vocabulary used in their textbooks and lectures as related to their prior research experiences and personal interests (e.g., generating possible directional hypothesis for studies in which they participated). Students also examined published studies to identify course-related vocabulary (e.g., narrative, case study). Targeted vocabulary was revisited routinely, with new terms explored as required. We frequently described word-learning exercises that we completed with our classes during our debriefing sessions:

I had all of the 16 words in a bag and everyone pulled out one word and then as a group we put them into three categories [research design, data collection, data analysis] (Jacqueline).

We did the same thing. I gave them time to work in pairs and try to find as may things as they could.... Then we just talked about grouping them and then we reviewed the [instructional] slide. So very similar. (Vera).

This exercise, along with the accompanied small group and whole class discussions, is an example of $\mathrm{Li}$ and Cutting's (2011) grouping and associating/elaborating strategies, which represent important memory strategies for vocabulary learning.

We also recognized the potential of various technologies, including audio recording and language translation devices, in supporting students' understanding and use of research terminology. Since we were unable to monitor students' use of these technologies (i.e., because of Mandarin text), encouraging students to use these technologies in class required an element of trust, which at times may have been misused (e.g., text messaging, surfing the Internet). However, overall we believed that having students use technology and digital resources when completing course activities helped to ensure that they remained engaged with the tasks at hand and facilitated their learning. Early on in the course Vera noted "I see the appropriate use of technologies a lot...They are using their thesaurus or translators," and added that "one of the things that I was most impressed with" was the students' appropriate, adept, and spontaneous use of technology.

Finally, in an attempt to reduce the linguistic challenges students would experience related to knowledge demonstration, we scaffolded assignments (group and individual) by providing step-by-step prompts for complex and layered questions. We also structured assignments so that students identified perceived methodological strengths as well as possibilities for improvement in order to be respectful of Chinese students' reported discomfort participating in Westernized notions of critique that 
often emphasize deficits over strengths (Durkin, 2011). In doing this, we hoped to provide students with a comfortable format to engage in critique (Durkin, 2011) and one that minimized the assessment of linguistic skills per se in favor of knowledge application.

Providing direct, teacher-centered instruction of critical researchrelated vocabulary and concepts, encouraging the use of technological supports including language translators, and scaffolding assignments seemed to facilitate students' learning. We also believe that students responded favorably to our attempt at providing culturally sensitive instruction. That is, the instructional approaches adopted here largely were consistent with Confucian-based pedagogy that embraces active memorization through understanding, practicing, and reviewing ( $\mathrm{Li} \&$ Cutting, 2011). We concur with Gordon (2008) that using constructivist pedagogy requires a balance between educator- and student-directed learning activities, and that instructors may, at times, need to assume more formal approaches to teaching, especially as related to unfamiliar yet foundational information.

\section{Fostering a Collaborative Environment}

Question answering. Throughout the planning and development of the research course, we were committed to using constructivist learning approaches that supported the co-creation of knowledge and understanding (Yilmaz, 2008). Consistent with Parris-Kidd and Barnett's findings (2011), our students initially appeared more comfortable engaging in instructordirected approaches than student-centered ones, especially those that involved question-answering and application activities. In response, we attempted to create a classroom environment that normalized question answering and discussion, as well as encouraged risk taking, fostered trust, and facilitated the co-creation of learning. We believed that the use of direct instruction and scaffolding satisfied Chinese students' preference for the inclusion of teacher-directed instruction (Parris-Kidd \& Barnett, 2011). Similarly, we believed that the reiteration and explanation of the importance of collaborative learning processes supported and encouraged students' engagement in a variety of activities intended to consolidate and extend their independent learning (Gordon, 2008).

Throughout the course, we encouraged all students to engage in question answering by incorporating it as an integral component of our instruction and by providing them with time to consider possible responses (individually, pairs, or in small groups). In order to increase students' comfort levels in providing responses, especially when they were uncertain about content materials or expressing opinions, we prefaced the questioning process by explaining its pedagogical value and by providing exemplars 
related to their enhanced levels of understanding. Vera described her approach as:

I tell people up front I am always going to be calling on somebody. So I will call everyone at least once in a class. And I make a big deal about it. You know, 'that's just the way it is and we are all about risk taking and there are no right or wrong answers. We can help each other but you know, I will always be calling on people.'

Furthermore, we emphasized the importance of thoughtful and considered responses over correctness per se, with students encouraged (and at times, directed) to call upon each other for assistance and elaboration when formulating responses. By valuing students' responses as points for initial discussion, we prompted learners to confirm, gently challenge, and extend each other's ideas. Even if whole-class discussions were not students' preferred communication mode, students still provided quality responses. Vera remarked "What I find amazing is more often than not, I am pleasantly surprised with what [students] come up with. They don't always put up their hand or say anything, but if you really call them out on it” their comments demonstrate a deep level of understanding.

At the same time, we were cognizant of the ways in which we delivered our feedback. We were sensitive that accepting students' contributions, when corrections or modifications were required, necessitated a gentle and supportive approach so that we did not inadvertently discourage future class participation.

I have to watch how I say those things ... because in a domestic class you can say...'hold that thought,' you know what I mean, but to tell anyone [here] that their point is wrong, I have to be a little more sensitive. (Vera)

Yes and I actually struggle with that because today they were giving the definitions and they weren't right...So I said 'okay I think maybe we are confusing a few of the terms here, let's talk about [it]' but I agree it is really challenging. I don't want to dissuade them from contributing but I also don't want other people to mishear and then think a term [is correct]. (Jacqueline)

Providing feedback in a sensitive manner was particularly crucial given Chinese students' initial reluctance to engage in class discussions (ParrisKidd \& Barnett, 2011) and that sharing their thoughts verbally could be perceived as a risky endeavor. We hoped that question answering became an anticipated, normalized, and collaborative activity that minimized Chinese 
students' reported discomfort with speaking in class (Durkin, 2011; Liu \& Jackson, 2011; Zhang, 2016).

Small group activities. We incorporated intensive, small-group application activities across all of our classes. Again, we informed students about the value of working in groups, reinforced the importance of quality peer feedback, and acknowledged enhanced quality through collaborative efforts. When recalling the explanation she provided to her class, Jacqueline reflected, "I said this is why we do group work because if you were to submit it on your own you maybe would not have had the right answer but here you can work it out and learn from each other."

Small group activities also were designed to provide students with opportunities to apply foundational course concepts in ways that were meaningful to the students as individuals, elaborate on ideas presented in their textbook, and generate exemplars for large group sharing. Student responses became the materials upon which new ideas were applied and extended, reinforcing learning as a socially constructed process and one that involved individual meaning making. For example, Jacqueline described how she had students build upon their ideas over a number of classes:

They had created their own topics previously as part of the research question and sub-question development so I had them get back in those original partners... and create three interview questions. Then I [changed] those partners with someone else, so they each had the chance to interview and to respond to the questions.

In order to assist student engagement in such discussions and activities in meaningful ways, students often participated in first-language deliberations. While these conversations typically unfolded as part of pair and group activities, there were times that such discussions were required during lecture. For example, when presenting a particularly difficult concept, Jacqueline described stopping her lecture and directing students to confirm their understandings with each other.

At one point I had a bunch of students talking over me in Mandarin and so I said 'you obviously need to be talking about something' because they do not typically do that [interrupt lecture]. So I said 'I am just going to give you a second because I have obviously said something that doesn't make sense or there are a couple of people who don't understand.' .... I think that it is really important that they have the ability to converse with their classmates because that language barrier is so great for some of them. 
A conundrum for us as instructors was that we were outsiders to such conversations, reluctant to interrupt students' ongoing discussions for fear of disrupting or impeding the learning process, and yet simultaneously unable to monitor and interject appropriately. These situations poignantly called into question our capacity as facilitators. We needed to rely on students' reported understandings and observations of their nonverbal behaviours (e.g., gesticulating at the power point, searching in the textbook) in order to assess their informal learning experiences. Jacqueline described the importance of these observations to her students:

'I don't always know what you're speaking about in Mandarin...but body language is really indicative.... One time when I asked you to speak [to each other in Mandarin], everyone was gesticulating at the screen....when you are pointing at the screen I can tell you are engaged in the material.'

Just as we encouraged our students to have trust in our pedagogical processes, we chose to trust students to complete tasks responsibly and engage with each other respectfully, in part, relying on our explicit discussions about the benefits of collaborative learning. Our trust seemingly was reinforced through students' provision of quality responses and engagement in the learning process.

\section{FINAL CONSIDERATIONS AND IMPLICATIONS}

In this paper, we document some of our instructional experiences and insights as related to teaching a mandatory research methods course to a group of predominantly Chinese graduate students enrolled in a cohort program. We conceptualize our discussions in context of honoring students' reported research experiences, facilitating their acquisition of subjectspecific vocabulary, and fostering a collaborative learning environment in ways that we believed are sensitive to Chinese students' cultural practices and learning preferences. We believe that the instructional practices reported here anticipate some of the pedagogical, social, and linguistic challenges reported by Chinese students (e.g., Lin \& Scherz, 2014; Zhang, 2016) and are consistent with effective pedagogical practices in general. These instructional practices also complement and extend those advocated by others who work with international students (e.g., Durkin, 2011; Li \& Cutting, 2011; McLean \& Ransom, 2005) or who teach research methods courses to graduate students (Early, 2013; Rodriguez \& Toews, 2005). Through our varied instructional formats and activities, we hoped to be responsive to our students as individuals. At the same time, we acknowledge the continuum of student openness to the instructional approaches presented 
here and caution against overgeneralizing one instructional experience or viewing any particular instructional approach as a panacea.

We also acknowledge that our experiences were bound within the parameters of instructing in a cohort model that minimized international students' interactions with domestic peers and intensified interactions with other international students who largely share the same first-language and cultural practices. Working within the cohort framework where peers shared similar characteristics likely facilitated students' initial acculturation experiences (Zhou et al., 2011) and supported the implementation of many of our instructional decisions (e.g., direct vocabulary instruction, firstlanguage discussions for small-group activities). At the same time, the cohort model limited opportunities for students to observe and gain insights from their domestic peers with respect to the research process and participation in constructivist learning activities (Zhou et al., 2011). Most importantly, we recognize the absence of student voices in this study, situating our recommendations within the context of our own perceptions and biases. To this end, we encourage future research that explores connections between instructors' attempts to provide culturally and linguistically diverse instruction and students' perceptions of these efforts.

With continued reflection in writing this paper, we recognize several factors contributed to our willingness to teach international students. We share personal beliefs supporting internationalization efforts on campus as well as a sense of responsibility for providing these students with meaningful instruction (Cao et al., 2014) that may, in part, be reflective of our own international travels and studies (Trice, 2003) as well as our disciplinary membership (Sawir, 2011). In addition, our professional commitments at the time were such that there were optimal opportunities for considerable preparation, along with ongoing course planning and lesson reflection, and by extension, participation in this study. We willingly drew upon and learned from each other's modest previous experiences working with international student cohorts. Finally, our perceptions related to students' increased comfort and receptiveness to our instructional efforts were powerful motivators for our continued efforts. Our experiences mirror Cao and colleagues' (Cao et al., 2014) conclusions that instructors' sense of responsibility and readiness, as well as perceptions of students' acquisition of knowledge, promote and sustain faculty involvement with international students.

We also believe that the opportunity to co-instruct increased our willingness to engage in the teaching of this course and student cohort. Coinstruction provided an impetus for ongoing discussions related to our pedagogical experiences as well as provided a platform for collaborative instructional planning, problem solving, and decision-making. Overall this type of engagement worked to reduce the sense of isolation that is often 
inherent in postsecondary instruction and supported our sense of readiness, creativity, and empowerment to teach in this context (Bryant et al., 2014). In these ways, co-instruction was an important element underlying our attempts to provide culturally and linguistically sensitive instruction and one that warrants further exploration in terms of promoting effective pedagogy when working with international students. We wonder whether other faculty who work with international students would welcome and benefit from the opportunity to participate in informal yet sustained course-specific discussions while engaged in course delivery.

As faculty are an integral component of the student experience and as the number of international students attending graduate studies in Canada is anticipated to increase (Government of Canada, 2015), there is a continued need for instructors to engage in culturally-sensitive instruction that supports these students' linguistic abilities, respects their reported experiences, and honors their instructional preferences. We leave this research study with a renewed sense of commitment to ourselves as coinstructors and to our students in terms of negotiating culturally sensitive instruction within the context of this mandatory research course. We remain committed to utilizing instructional practices that are responsive to students' prior learning and research experiences and we intend to seek out new approaches that allow us to continue these commitments. In the interim, we offer our initial instructional experiences here in hopes that they may provide insights to other research-course instructors who work with Chinese graduate students.

\section{REFERENCES}

Altbach, P. G., \& Reisberg, L. (2013). The pursuit of international students in a commercialized world. International Higher Education, 73, 1-10.

Andrade, M. S., (2006). International students in English-speaking universities: Adjustment factors. Journal of Research in International Education, 5(2), 131-154.

Armstrong, D., Gosling, A., Weinman, J., \& Marteau, T. (1997). The place of interrater reliability in qualitative research: An empirical study. Sociology, 31(3), 597-606. doi: 10.1177/0038038597031003015

Bryant, L. H., Niewolny, K., Clark, S., \& Watson, C. E. (2014). Complicated spaces: Negotiating collaborative teaching and interdisciplinarity in higher education. Journal of Effective Teaching, 14(2), 83-101.

Canadian Association for Graduate Studies. (2006). A profile of Master's degrees in Canada. Retrieved from

http://www.cags.ca/documents/publications/best_practices/CAGSMaster.pdf

Cao, Y., Li, X., Jiang, A., \& Bai, K. (2014). Motivators and outcomes of faculty actions towards international students: Under the influence of internationalization. International Journal of Higher Education, 3(4), 4963. doi:10.5430/ijhe.v3n4p49 
Charmaz, K. (2014). Constructing grounded theory. Los Angeles, CA: Sage.

Citizenship and Immigration Canada [CIC]. (2015). International students with a valid permit on December $31^{\text {st }}$ by top 50 countries of citizenship, 2004 to 2013.

http://www.cic.gc.ca/english/resources/statistics/facts2013/temporary/42.asp

Cortazzi, M., \& Jin, L. (1996). English teaching and learning in China. Language Teaching, 29(2), 61-80.

Durkin, K. (2011). Adapting to Western norms of critical argumentation and debate. In L. Jin and M. Cortazzi (Eds.), Researching Chinese learners: Skills, perceptions and intercultural adaptations. (pp. 274-291). New York, NY: Palgrave MacMillan.

Early, M. A. (2013). Graduate students' expectations of an introductory research methods course. Education Research Quarterly, 37(1), 48-59.

Enfield, M., \& Stasz, B. (2011). Presence without being present: Reflection and action in a community of practice. Journal of the Scholarship of Teaching and Learning, 11(1), 108-118.

Given, L. M. (2008). Action research. In The SAGE Encyclopedia of Qualitative Research Methods. (pp. 4-7). Thousand Oaks, CA: Sage.

Gordon, M. (2008). Between constructivism and connectedness. Journal of Teacher Education, 59(4), 322-331. doi: 10.1177/0022487108321379

Government of Canada. (2015). Evaluation of the international student program: Profile of international students. Retrieved from http://www.cic.gc.ca/english/resources/

Han, X., Han, X., Luo, Q., Jacobs, S., \& Jean-Baptiste, M. (2013). Report of a mental health survey among Chinese international students at Yale University. Journal of American College Health, 61(1), 1-8.

Kim, D., Pan, Y., \& Park, H. S. (1998). High-versus low-context culture: A comparison of Chinese, Korean, and American cultures. Psychology and Marketing, 15(6), 507-521.

Knight, J. (2003). Updating the definition of Internationalization. International Higher Education, 33, 2-3.

Knowles, M. S. (1981). The modern practice of adult education: From pedagogy to andragogy (revised and updated ed.). Englewood Cliffs, NJ: Prentice Hall.

Ku, H-Y., Lahman, M. K. E., Yeh, H-T., \& Cheng, Y-C. (2008). Into the academy: Preparing and mentoring international doctoral students. Educational Technology Research and Development, 56, 365-377. doi:10.1007/s11423007-9083-0

Li, J. Q., Liu, X., Wei, T., \& Lan, W. (2013). Acculturation, internet use, and psychological well-being among Chinese international students. Journal of International Students, 3(2), 155-166. 
Li, X., \& Cutting, J. (2011). Rote learning in Chinese culture: Reflecting active Confucian-based memory strategies. In L. Jin and M. Cortazzi (Eds.), Researching Chinese learners: Skills, perceptions and intercultural adaptations. (pp. 21-42). New York, NY: Palgrave MacMillan.

Li, X., DiPetta, T., \& Woloshyn, V. E. (2012). Why do Chinese students complete a Master of Education degree in Canada? What are their experiences? Canadian Journal of Education, 35(2), 149-163.

Lin, S-Y., \& Scherz, S. D. (2014). Challenges facing Asian international graduate students in the US: Pedagogical considerations in higher education. Journal of International Students, 4(1), 16-33.

Lincoln, Y. S., \& Guba, E. G. (1985). Naturalistic inquiry. Beverly Hills, CA: Sage.

Liu, M., \& Jackson, J. (2011). Reticence and anxiety in oral English lessons: A case study in China. In L. Jin and M. Cortazzi (Eds.), Researching Chinese learners: Skills, perceptions and intercultural adaptations. (pp. 119-137). New York, NY: Palgrave MacMillan.

Louie, K. (2005). Gathering cultural knowledge: Useful or use with care? In. J. Carroll \& J. Ryan (Eds.), Teaching international students (pp. 17-25). New York, NY: Routledge.

McLean, P., \& Ransom, L. (2005). Building intercultural competencies: Implications for academic skills development. In J. Carroll \& J. Ryan (Eds.), Teaching international students (pp. 45-62). New York, NY: Routledge

Nguyen, H. M. (2013). Faculty advisors' experiences with international graduate students. Journal of International Students 3(2), 102-116.

Parris-Kidd, H., \& Barnett, J. (2011). Cultures of learning and student participation: Chinese learners in a multicultural English class in Australia. In L. Jin and M. Cortazzi (Eds.), Researching Chinese learners: Skills, perceptions and intercultural adaptations. (pp. 21-42). New York, NY: Palgrave MacMillan.

Rodriguez, A., \& Toews, M. L. (2005). Training students to be better consumers of research: Evaluating empirical research reports. College Teaching, 53(3), 99-101.

Ryan, J., \& Carroll, J. (2005). 'Canaries in the coalmine': International students in Western universities. In. J. Carroll \& J. Ryan (Eds.), Teaching international students (pp. 3-10). New York, NY: Routledge.

Ryan, J., \& Hellmundt, S. (2005). Maximising international students' 'cultural capital'. In. J. Carroll \& J. Ryan (Eds.), Teaching international students (pp. 13-16). New York, NY: Routledge.

Sawir, E. (2011). Academic staff response to international students and internationalizing the curriculum: The impact of disciplinary differences. International Journal of Academic Development, 16, 45-57. http://dx.doi.org/10.1080/1360144X.2011.546224

Schwandt, T.A. (2000). Three epistemological stances for qualitative inquiry: Interpretivism, hermeneutics, and social constructivism. In N. Denzin and Y. Guba (Eds.), Handbook of qualitative research ( $2^{\text {nd }}$ ed., pp. 189-213). Thousand Oaks, CA: Sage.

Shenton, A. K. (2004). Strategies for ensuring trustworthiness in qualitative research projects. Education for Information, 22(2), 63-75. 
Sherry, M., Thomas, P., \& Chui, W. H. (2010). International students: A vulnerable student population. Higher Education, 60(1), 33-46.

Sue, D. (2013). Counselling issues within the Asian community. In M. H. France, M. del Carmen Rodríguez, \& G. G. Hett (Eds.), Diversity, culture and counselling: A Canadian perspective ( $2^{\text {nd }}$ ed., pp. 92-103). Calgary, AB: Brush Education.

Trice, A. G. (2003). Faculty perceptions of graduate international students: The benefits and challenges. Journal of Studies in International Education, 7(4), 379-403.

Tsai, P., \& Wong, Y. J. (2012). Chinese and Taiwanese international college students' participation in social organizations: Implications for college counseling professionals. Journal of College Counseling, 15(2), 144-156.

Universities Canada. (2014). Internationalization at Canadian Universities: Quick facts. Retrieved from http://www.univcan.ca/wpcontent/uploads/2015/07/quick-facts-internationalization-survey-2014.pdf

Vygotsky, L.S., (1986). Thought and language. Cambridge, MA: MIT Press.

Wood, D., Bruner, J. S., \& Ross, G. (1976). The role of tutoring in problem solving. Journal of Child Psychology \& Psychiatry \& Allied Disciplines, 17(2), 89100. doi: 10.1111/1469-7610.ep11903728

Yilmaz, K. (2008). Constructivism: Its theoretical underpinnings, variations, and implications for classroom instruction. Educational Horizons, 86(3), 161172.

Ying, H. (2012). Transitioning challenges faced by Chinese graduate students. Adult Learning, 23(3), 138-147. doi:10.1177/1045159512452861

Zhang, Y. (2016). International students in transition: Voices of Chinese doctoral students in a U.S. research university. Journal of International Students, 6(1), 175-194.

Zhou, Y., Topping, K., \& Jindal-Snape, D. (2011). Intercultural adaptation on Chinese postgraduate students and their UK tutors. In L. Jin and M. Cortazzi (Eds.), Researching Chinese learners: Skills, perceptions and intercultural adaptations. (pp. 233-249). New York, NY: Palgrave MacMillan.

JACQUELINE L. BERES, MEd, is a doctoral student in the Joint $\mathrm{PhD}$ in Educational Studies program at Brock University. She is interested in graduate student socialization, the scholarship of teaching and learning, research methods, and international students. Email: Jacqueline.Beres@Brocku.ca

VERA E. WOLOSHYN, PhD, is a professor of education. She teaches undergraduate and graduate-level courses in cognition and learning, educational psychology, service learning, and research methods. Her primary research interests include the exploration of effective learning environments for diverse learners including international students. Email: vwoloshyn@brocku.ca 